\title{
Experimental Studies on Magnetorheological Brake for Automotive Application
}

\author{
Satyajit R. Patil"and Suresh M. Sawant \\ Mechanical Engineering Dept., Rajarambapu Institute of Technology, \\ Rajaramnagar Shivaji University, Kolhapur, MS - 415 414, INDIA \\ *Email: satyajit.patil@ ritindia.edu \\ Phone: +912342 220329; Fax: +912342 220989
}

\begin{abstract}
Automotive brake performance in terms of stopping time largely influences the occupant and pedestrian safety. Conventional hydraulic brakes are being used despite the delayed time response of around $200 \mathrm{~ms}$. This work envisages magneto-rheological (MR) brake, as an automotive service brake owing to its response time of about 15-20 ms. The work proposes design of shear mode MR brake for the automotive application under consideration. Preliminary magnetostatic analysis is done to estimate the output torque of MR brake. It is followed by experimental evaluation of the MR brake prototype in terms of output torque and temperature rise. Details of experimental set up and the test procedure are presented. Variation of output torque with input current and speed is recorded along with results of thermal evaluation. Finally, correlation analysis is used to ascertain the effect of influencing parameters viz. current and speed on output torque of MR brake. Regression equation is obtained to relate the torque output with input parameters. Though the influence of input parameters is characterized, the study underlines the need for high yield stress MR fluids or breakthrough design approach in order for MR brake to be considered for automotive application.
\end{abstract}

Keywords: MR brake, experimental evaluation, automotive application, correlation analysis.

\section{INTRODUCTION}

In view of road safety, performance of automotive brakes is an important issue which needs serious attention. Conventional automotive hydraulic brakes suffer from delayed response time (200-250 ms), loss of effectiveness due to brake lining wear and brake fade [1]. It would be a worthwhile idea to explore the potential of magneto-rheological (MR) brakes for automotive applications owing to their fast response time, which shall help reduce stopping time and distance, key brake performance parameters. Such an application has not been commercialized as yet for automotive purpose and hence need some investigations in terms of braking torque output and characterization. The objective of this research is to explore MR brake (MRB) for a light weight two wheeled application owing to its low brake torque requirement.

MR brake belongs to the family of MR devices like MR damper, elastomer, clutch etc. which use magneto-rheological fluids (MRF) for their successful operation. MR fluids are suspensions of carbonyl iron particles in oil (usually silicone oil) along with certain additives, which change their viscosity within few milliseconds when subjected to magnetic field [1]. This phenomenon, called 'MR effect' is reversible which means the 
fluids gain their liquid state when the magnetic field is removed. Typical MR brake shown in Figure 1 operate in shear mode.

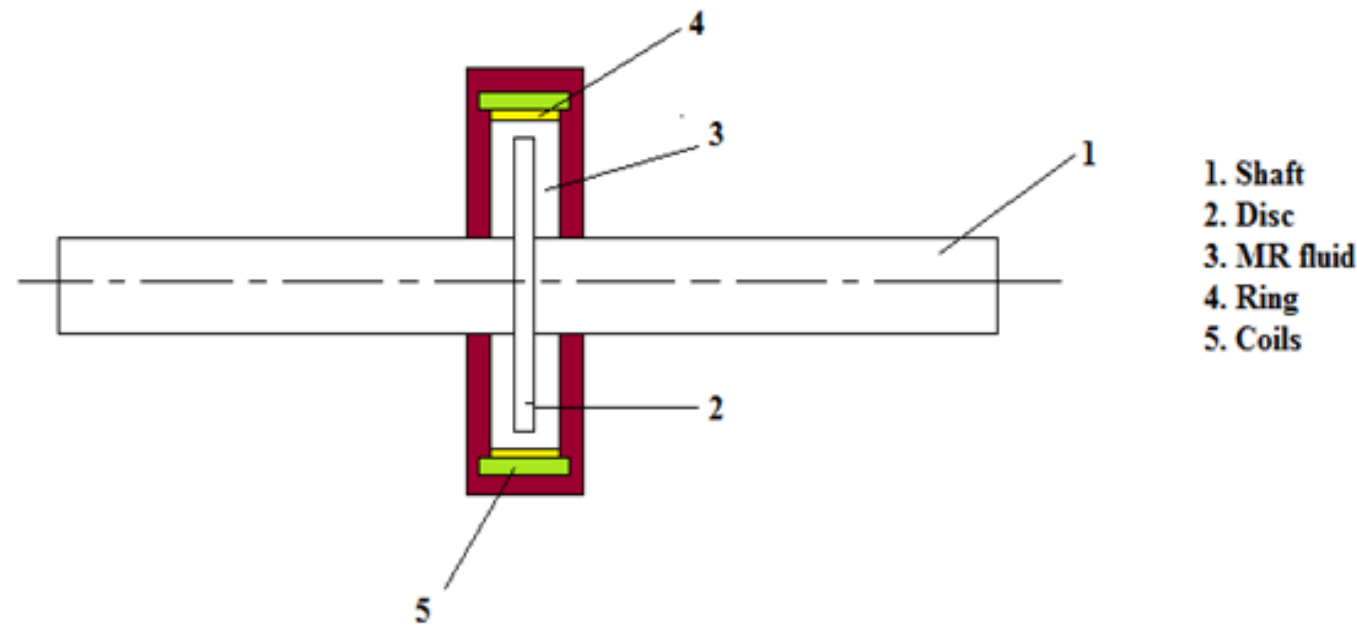

Figure 1. Schematic of typical MR brake.

The MR fluid in the MR gap around the disc applies shear force on the disc, when subjected to magnetic field by the electromagnet. Thus, the disc and hence the shaft on which the disc is mounted, are decelerated owing to the MR effect. The total braking torque $\left(\mathrm{T}_{\mathrm{b}}\right)$ is comprised of two elements: torque due to magnetic field $\left(\mathrm{T}_{\mathrm{H}}\right)$ and torque due to plastic viscosity $(\mathrm{T} \mu)$ as shown in following equations [2].

$\mathrm{T}_{\mathrm{b}}=\mathrm{T}_{\mathrm{H}}+\mathrm{T}_{\mu}$

$\mathrm{T}_{\mathrm{H}}=\frac{2 \pi}{3} \mathrm{NKH}^{\beta}\left(\mathrm{r}_{\mathrm{z}}^{3}-\mathrm{r}_{\mathrm{j}}^{3}\right)$

$\mathrm{T}_{\mu}=\frac{\pi}{2 \mathrm{~h}} \mathrm{~N} \mu_{\mathrm{p}}\left(\mathrm{r}_{\mathrm{z}}^{4}-\mathrm{r}_{\mathrm{j}}^{4}\right) \omega$

Where, $\mathrm{N}$ is number of discs, $\mathrm{H}$ is magnetic field intensity, $\mathrm{r}_{\mathrm{z}}$ and $\mathrm{r}_{\mathrm{j}}$ are outer and inner radii of disk, $h$ is thickness of MR fluid gap, $\omega$ is angular velocity of disc and; $K$ and $\beta$ are MR fluid dependent constant parameters. Hence, the parameters influencing the braking torque of MRB are: number of discs $(\mathrm{N})$, The dimensions and configuration of magnetic circuit $\left(\mathrm{r}_{\mathrm{z}}, \mathrm{r}_{\mathrm{j}}\right.$ and other structural parameters) and magnetic field intensity of MR fluid $(\mathrm{H})$ which is dependent on applied current density in electromagnet and materials used in magnetic circuit. However, the viscous component $\left(\mathrm{T}_{\mathrm{H}}\right)$ is desired to be low as it contributes to the viscous drag during off-state of the brake.

There have been some studies on general purpose MR brakes. Li and Du [3], one of the early works, designed and characterized typical MR brake. Park et al. [1,4] and Karakoc et al. [2] have explored MR brake for an automotive application. Sukhwani and Hirani [5] designed and characterized high speed MR brake. They investigated effect of MR gap and speed on torque output of MR brake. Nguyen and Choi $[6,7,8]$ contributed to the research on MR brakes in the form of design and optimization studies. They developed an optimized MR brake for a motorcycle application [8]. Assadsangabi et al. [9] and Younis et al. [10] used GA and SEMURE optimization algorithms to optimize the MR brake design. Marannano presented magnetostatic finite element simulation in 
order to estimate the output torque of MR brake envisaged for a mid-size car application [11]. Sarkar and Hirani $[12,13]$ explored squeeze mode MR brake in order to increase torque output from the MR brake and attempted parabolic-profile MR brake. Patil et al. [14] presented thermal analysis of automotive MR brake. Patil and Sawant [15] investigated reliability issues of MR brake. PID controller for MR brake control at various loads and speeds is presented by Abdullah et al. [16].

Mainly the research on MR brake is comprised of design, analysis, optimization and simulation studies. Some works have presented experimental evaluations on general purpose MR brake applications. MR brake for automotive applications has been explored in few cases. Earlier studies indicate low levels of torque outputs of MRB and hence unable to meet braking torque requirements of mid-size car applications. On account of its lower weight and lower value of top speed, the braking requirement of an application like e-bicycle, in terms of braking torque, is not demanding. Hence, the present work makes an effort to design and experimentally evaluate MR brake envisaged for an ebicycle. The brake is evaluated for torque output as well as temperature rise due to application of brake. An effort is made to evaluate the brake output for drive cycle as well. In order to validate the experimental findings, correlation analysis is used and regression equation for torque output is obtained.

\section{DESIGN OF MR BRAKE FOR PROPOSED APPLICATION}

MRB is designed for light weight two-wheeler application like e-bicycle owing to its low braking torque requirement. The main specifications of this e-bicycle are presented in Table 1.

Table 1. Specifications of e-bicycle.

\begin{tabular}{ll}
\hline Parameter & Specification \\
\hline Top speed & $25 \mathrm{~km} / \mathrm{h}$ \\
Mass (unladen condition) & $50 \mathrm{~kg}$ \\
Tyre size & $18 \times 2.125$ \\
Wheelbase & $1180 \mathrm{~mm}$ \\
Wheel radius & $228.72 \mathrm{~mm}$ \\
Batteries & Lead-acid $36 / 48 \mathrm{~V} 10 / 20 \mathrm{Ah}$ \\
Electric motor & PMDC $180 / 240 \mathrm{~W}$ \\
\hline
\end{tabular}

Center of gravity of the e-bicycle is determined using vehicle dynamics principles. Considering deceleration requirements as per IS standards (IS 14664:1999), braking forces and thereby braking torques on front and rear wheels are calculated. At top speed of $25 \mathrm{~km} / \mathrm{h}$ and considering deceleration of $0.5 \mathrm{~g}$, the braking torque requirement for the e-bicycle is found to be $160 \mathrm{Nm}$. Single disc MRB with MR gap of $1 \mathrm{~mm}$ is proposed. The proposed configuration is presented in Table 2. Materials for various elements of MRB are selected based on structural, magnetic and thermal considerations [2] and presented in Table 3. 
Table 2. Configuration of proposed MR brake.

\begin{tabular}{ll}
\hline Parameter & Configuration selected \\
\hline Type & Disc brake \\
Geometry & Rotary \\
No. of discs & One \\
MR fluid & MRF-132DG \\
Gap size & $1 \mathrm{~mm}$ \\
\hline
\end{tabular}

Table 3. Material selection for MR brake.

\begin{tabular}{clll}
\hline Sr. No. & Element & Material & Justification \\
\hline 1 & Shaft & $\begin{array}{l}\text { 304 stainless } \\
\text { steel }\end{array}$ & $\begin{array}{l}\text { Non-magnetic, good structural } \\
\text { strength } \\
\text { Permeability and less cost }\end{array}$ \\
2 & $\begin{array}{l}\text { Shear disc and } \\
\text { stator }\end{array}$ & AISI 1018 & Aluminum \\
Casing & $\begin{array}{l}\text { Light in weight, thermal } \\
\text { conductivity } \\
\text { Permeability and less cost }\end{array}$ \\
\hline
\end{tabular}

Based on the available space envelope for mounting of the brake on the wheels of the e- bicycle, the overall size is estimated to be around $152-202 \mathrm{~mm}$ (6 to 8 inches). Magnetic circuit is designed for magnetomotive force i.e. NI. For braking torque of 160 $\mathrm{Nm}$, the required value of shear stress is estimated to be $46.83 \mathrm{kPa}$. Referring curve of shear stress vs. magnetic field intensity for MRF-132DG [1], the value of magnetic field intensity $\mathrm{H}$ is found to be $330 \mathrm{kA} / \mathrm{m}$ and corresponding magnetic flux density $\mathrm{B}_{\mathrm{f}}$, found from B-H curve of MRF-132DG is found to be 0.73 Tesla. Magnetic circuit with 238.73 amp-turns is proposed for the MRB. The CAD model developed based on this design is shown in Figure 2. Figure 3 (a) and (b) shows the MR brake prototype developed and used for experimental verification.

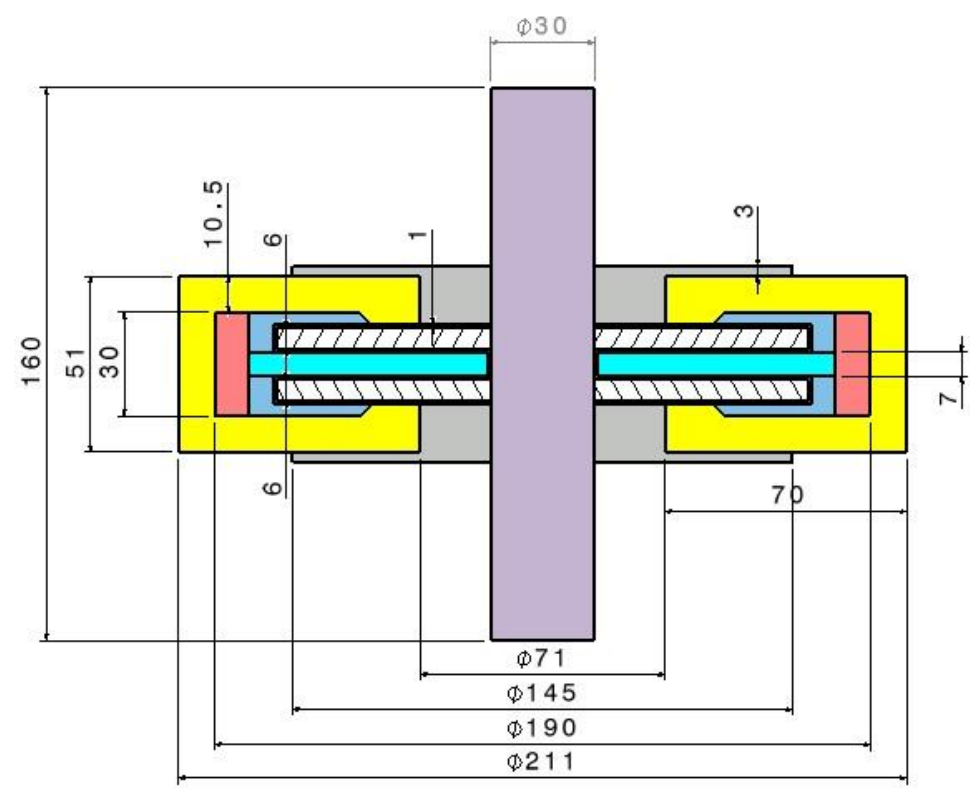

Figure 2. CAD model of proposed MRB. 


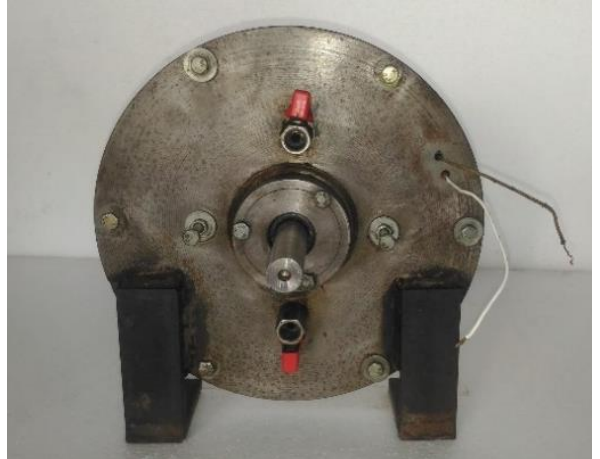

(a)

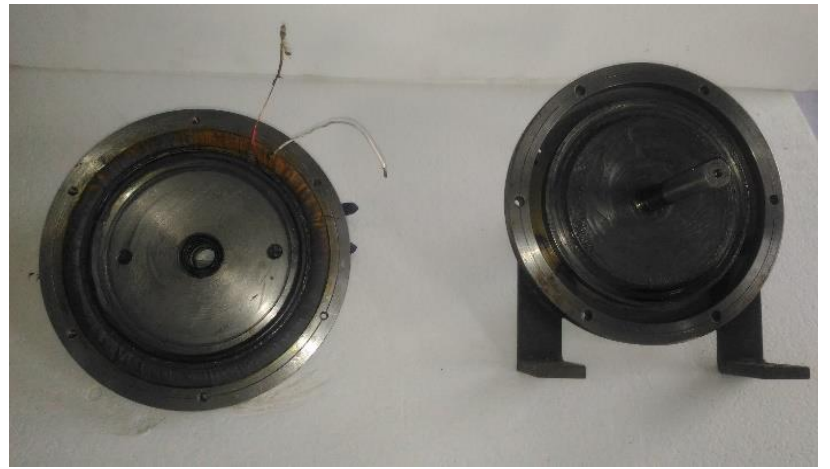

(b)

Figure 3. The MRB used for experimental evaluation.

\section{MAGNETOSTATIC ANALYSIS}

Magnetostatic analysis of the MRB is done using ANSYS to make preliminary estimation of the braking torque output of proposed MRB. PLANE13 element is used for 2D axisymmetric two-disc model of MR brake. Intensity of current through the coil represents the load in the analysis. The model is constrained with magnetic vector potential to be zero at outer boundary. The range of current applied to the coil is from 0 to $1.5 \mathrm{~A}$. The value of magnetic field intensity $(\mathrm{H})$ distribution generated by the MR brake model is obtained during the post processing. For each value of $\mathrm{H}$, the braking torque is calculated using Eq. (2). Figure 4 presents the magnetic field distribution within MR brake model. From the analysis, the obtained value of magnetic field intensity $(\mathrm{H})$ is $21.655 \mathrm{kA} / \mathrm{m}$ which is well within the saturation limit of $\mathrm{H}$ i.e. up to $250 \mathrm{kA} / \mathrm{m}$ [17]. Figure 5 shows the magnetic flux distribution (B) within the MR brake model.

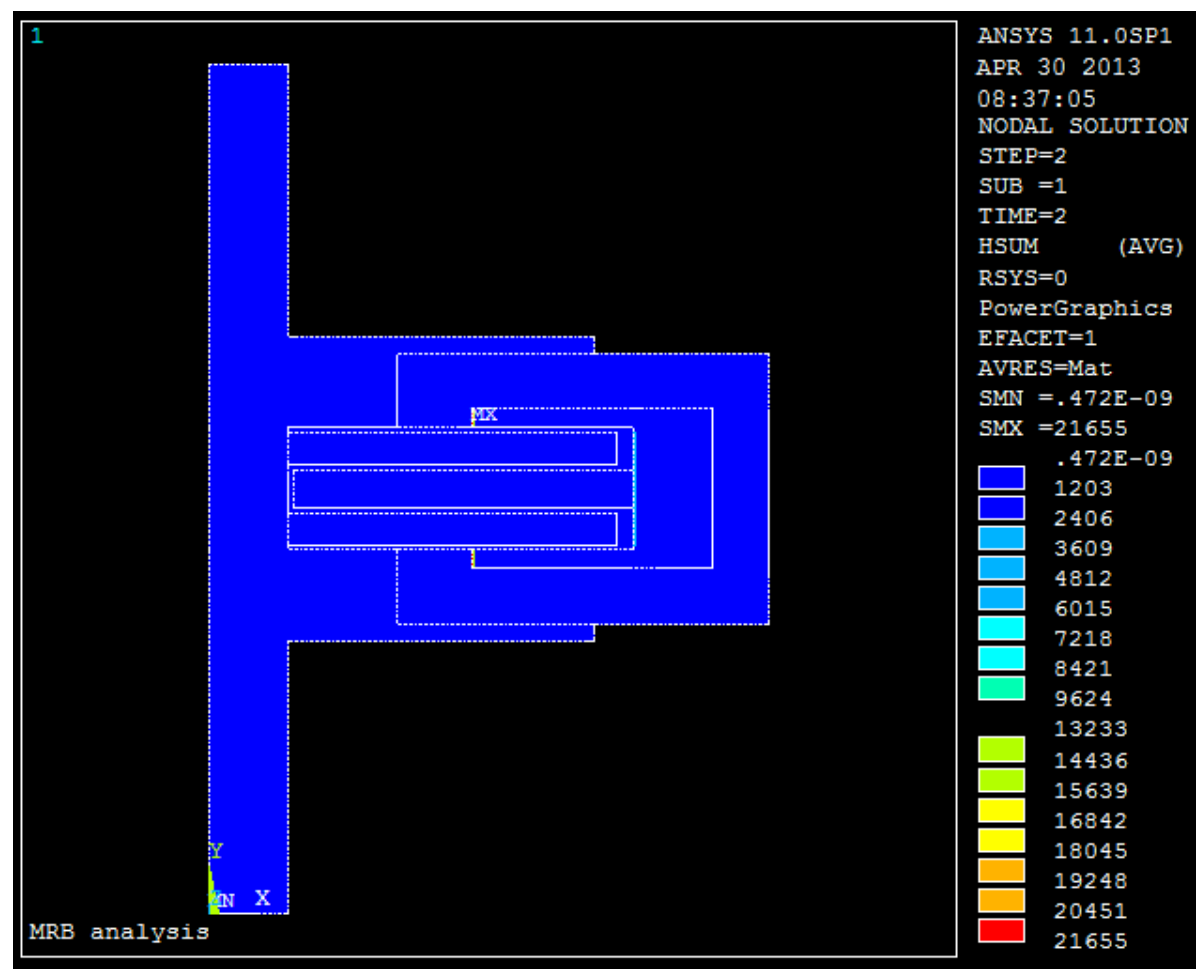

Figure 4. Distribution of magnetic field intensity within MR brake model. 


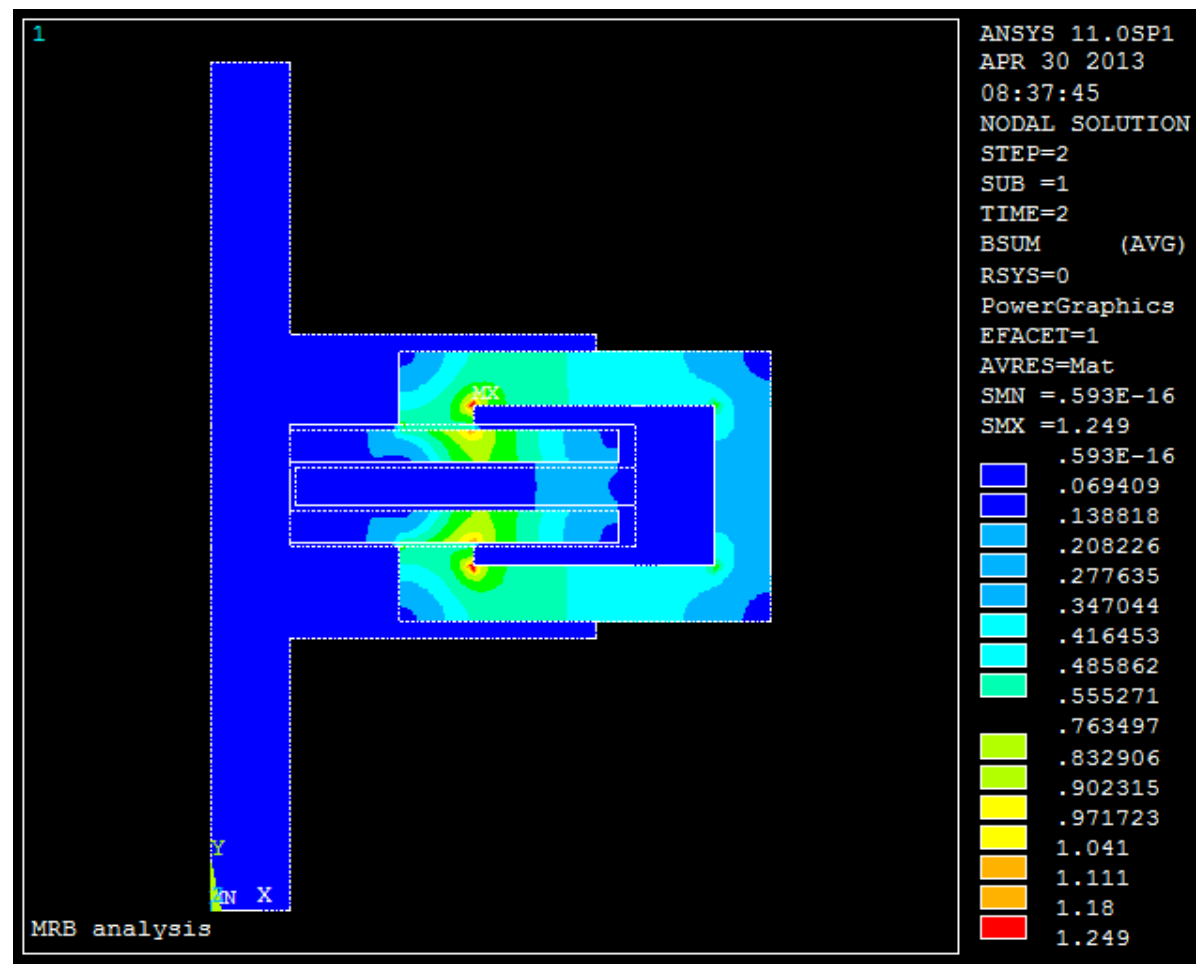

Figure 5. Distribution of magnetic flux density within MR brake model.

From analysis, the obtained value of B is equal to 1.2 Tesla, which is within the saturation limit of $\mathrm{B}(\mathrm{B}=1.65$ Tesla). The braking torque is calculated for various values of magnetic field intensity, which is presented in Table 4.

Table 4. Braking torque for various values of $\mathrm{H}$.

\begin{tabular}{ccccc}
\hline Current, I (A) & $\begin{array}{c}\text { Current } \\
\text { density, J } \\
\left(\mathrm{A} / \mathrm{mm}^{2}\right)\end{array}$ & $\begin{array}{c}\text { Magnetic field } \\
\text { intensity, H } \\
(\mathrm{kA} / \mathrm{m})\end{array}$ & $\begin{array}{c}\text { Magnetic flux } \\
\text { density, B } \\
(\text { Tesla })\end{array}$ & $\begin{array}{c}\text { Braking } \\
\text { torque, } \mathrm{T}_{\mathrm{H}} \\
(\mathrm{N} . \mathrm{m})\end{array}$ \\
\hline 0.2 & 0.43 & 7.218 & 0.4 & 7.37 \\
0.4 & 0.86 & 14.436 & 0.8 & 14.74 \\
0.6 & 1.29 & 21.655 & 1.2 & 22.12 \\
0.8 & 1.72 & 28.872 & 1.6 & 29.48 \\
1.0 & 2.15 & 36.088 & 2.1 & 36.84 \\
1.2 & 2.58 & 43.304 & 2.5 & 42.21 \\
\hline
\end{tabular}

From Table 4, it is seen that the braking torque obtained corresponding to the magnetic field intensity of $21.655 \mathrm{kA} / \mathrm{m}$, is equal to $22.12 \mathrm{~N} . \mathrm{m}$. For this value of $\mathrm{H}$, corresponding value of $\mathrm{B}$ is within saturation limit. The analysis indicates that the MR brake shall not be able to deliver the required torque output of 160 N.m.

\section{EXPERIMENTAL SETUP}

Experimental setup shown in Figure 6 consists of motor with reduction gearbox, torque sensor, speed sensor, control panel and torque display unit. A three phase $3 \mathrm{HP}$ AC motor is used as prime mover. For reduction of speed from 1440 to $450 \mathrm{rpm}$ (maximum speed 
for evaluation purpose), gearbox with 3:1 reduction ratio is used in the setup. A variable frequency control mechanism is selected as the motion control for AC motor. A $12 \mathrm{~V}$ power supply is used to provide input current to the electromagnet of MRB. ADI-RTech make in-line type torque sensor is used for measurement of braking torque generated by MRB prototype. Braking torque of MRB is sensed by torque sensor and output of sensor is given to a unit which displays the numeric braking torque in kgm. Flange type flexible couplings are used to connect the motor shaft, sensor shaft and brake shaft. Four pillow block bearings are used to support the shafts. The experimental setup is rested and bolted on a solid base frame. Infrared thermometer is used to measure rise in temperature of brake body; as heat is generated due to braking application. The setup was calibrated with the help of calibration fixture attachment attached to the setup. It allows known weight to be kept in the pan of the fixture that has an arm of known length. The torque thus produced i.e. the weight kept in the pan times the arm length is indicated by the torque display unit.

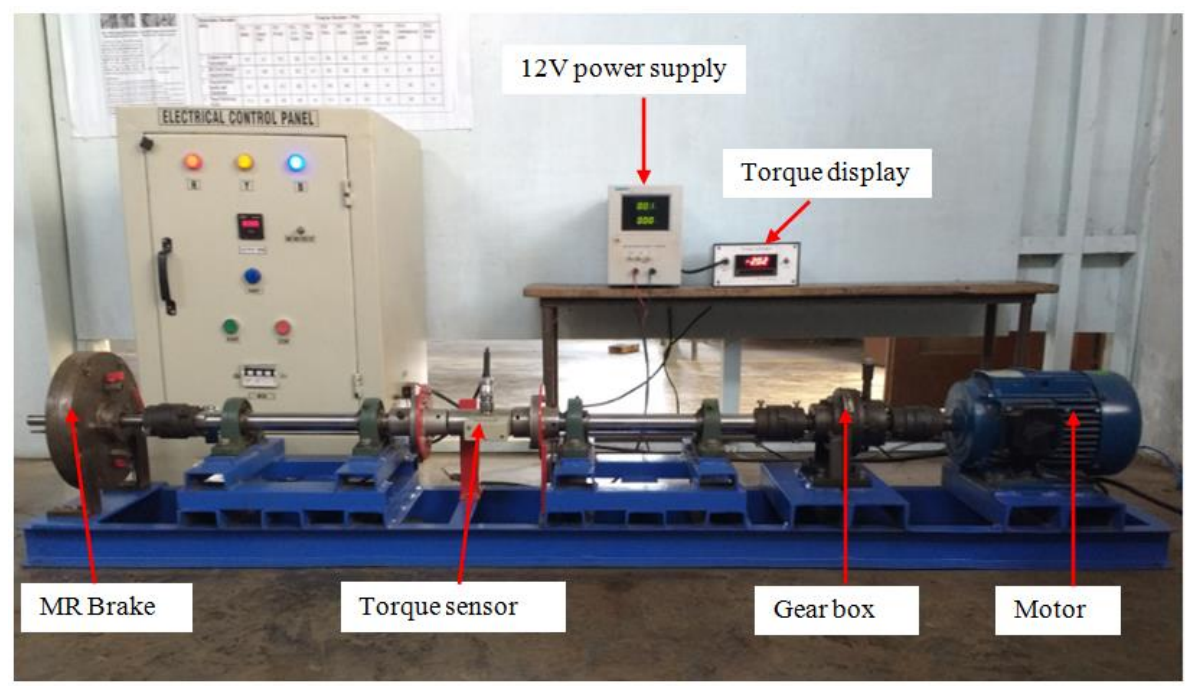

Figure 6. Experimental setup for MRB evaluation.

\section{Experimental Procedure for Performance Evaluation}

Steps followed to carry out experimental evaluation are listed below.

1. MRB is rotated for 2 or $3 \mathrm{~min}$. at $200-300 \mathrm{rpm}$. It ensures uniform distribution of magnetizable particles in carrier fluid around shear disk.

2. Off field braking torque (viscous torque) was recorded for various rotating speeds viz. 177, 235, 296 and $354 \mathrm{rpm}$ which corresponds to e-bicycle speeds of 10, 15, 20 and $25 \mathrm{~km} / \mathrm{h}$ on the road.

3. Now, desired current level was applied to the electromagnet and braking torque was recorded for various rotating speed levels. For a combination of current and speed, three readings were recorded, and the average value was considered as final observation. Temperature of body was recorded for each reading with the help of infrared thermometer.

4. Step 3 was repeated for various current values i.e. 1, 2, 3 and 3.5 A. The highest input current level range was chosen to be $3.5 \mathrm{~A}$, because further higher current level may cause saturation of magnetic field and thus there won't be increment in output torque. Also, it is observed that input current level up to $2 \mathrm{~A}$ is used in earlier studies $[2,5]$. 


\section{Magnetic Flux Density Measurement}

Magnetic flux density of electromagnet within the MRB was measured with the help of calibrated gauss meter. The setup for the measurement is shown in Figure 7. The measurement was taken with the help of probe at two positions, namely at the 'center' and at the outer periphery referred to as 'far away position' in this text. Magnetic flux density (B) was obtained in k.Gauss and converted into Tesla (1 Tesla $=10000$ Gauss). Magnetic field intensity $(\mathrm{H})$ in $\mathrm{A} / \mathrm{m}$ was calculated using Eq. (4) [12].

$$
B=-10^{-11} H^{2}+6 \times 10^{-6} H+0.156
$$

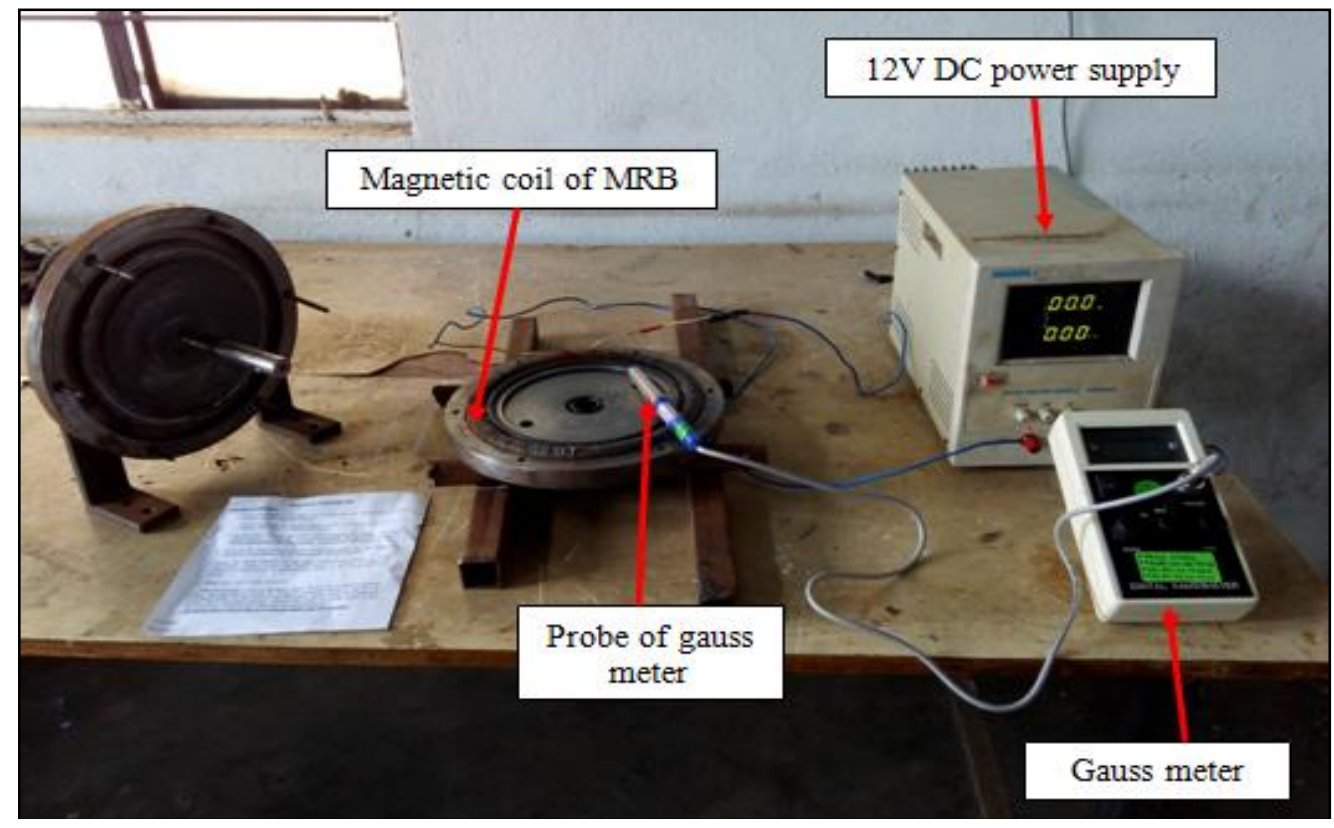

Figure 7. Setup for measurement of flux density.

\section{Experimental Evaluation for Output Torque}

This section presents the results of experimental evaluations carried out with MRF132DG as working fluid. Torque response and temperature were recorded for various current and speed inputs. As mentioned in above section, torque outputs were recorded for speeds of 177, 235, 296 and $354 \mathrm{rpm}$ and current levels of $1 \mathrm{~A}, 2 \mathrm{~A}, 3 \mathrm{~A}$ and $3.5 \mathrm{~A}$ using MRF-132DG.

\section{RESULTS AND DISCUSSION}

In Table 5, it was observed that magnetic field intensity achieved at $2.5 \mathrm{~A}$ is $78.58 \mathrm{kA} / \mathrm{m}$ at center position and $76.90 \mathrm{kA} / \mathrm{m}$ at far away position which is very low as compared to magnetic saturation limit of around $250 \mathrm{kA} / \mathrm{m}$ of MRF-132DG. The field intensity was observed to be slightly lower at far away position as compared to center position. Thus, need is felt to optimize the magnetic circuit within the MRB so as to improve the field intensity using the available space to accommodate maximum possible windings for the electromagnet. 
Table 5. Magnetic flux density and corresponding field intensity.

\begin{tabular}{ccccccc}
\hline $\begin{array}{c}\text { Current } \\
(\mathrm{A})\end{array}$ & \multicolumn{2}{c}{$\begin{array}{c}\text { Magnetic flux density } \\
(\mathrm{kGauss})\end{array}$} & \multicolumn{2}{c}{$\begin{array}{c}\text { Magnetic flux density, } \\
\text { B (Tesla) }\end{array}$} & \multicolumn{2}{c}{$\begin{array}{c}\text { Magnetic field intensity, } \\
(\mathrm{kA} / \mathrm{m})\end{array}$} \\
\hline & Center & far away & Center & far away & Center & far away \\
0.5 & 0.03 & 0.06 & 0.003 & 0.006 & 79.295 & 78.99 \\
1.0 & 0.05 & 0.11 & 0.005 & 0.011 & 79.091 & 78.476 \\
1.5 & 0.07 & 0.16 & 0.007 & 0.016 & 78.887 & 77.958 \\
2.0 & 0.08 & 0.21 & 0.008 & 0.021 & 78.785 & 77.434 \\
2.5 & 0.10 & 0.26 & 0.010 & 0.026 & 78.579 & 76.904 \\
\hline
\end{tabular}

Figure 8 presents variation of torque response with respect to current and speed for MRF-132DG as working fluid. It is seen that; braking toque increases with increase in speed and current. But effect of speed on braking torque is found to be negligible. Sharp rise in torque is observed with rise in current value. Similar observations are made from analytical evaluations of MRB. Maximum braking torque recorded for MRF-132DG was $25.89 \mathrm{Nm}$.

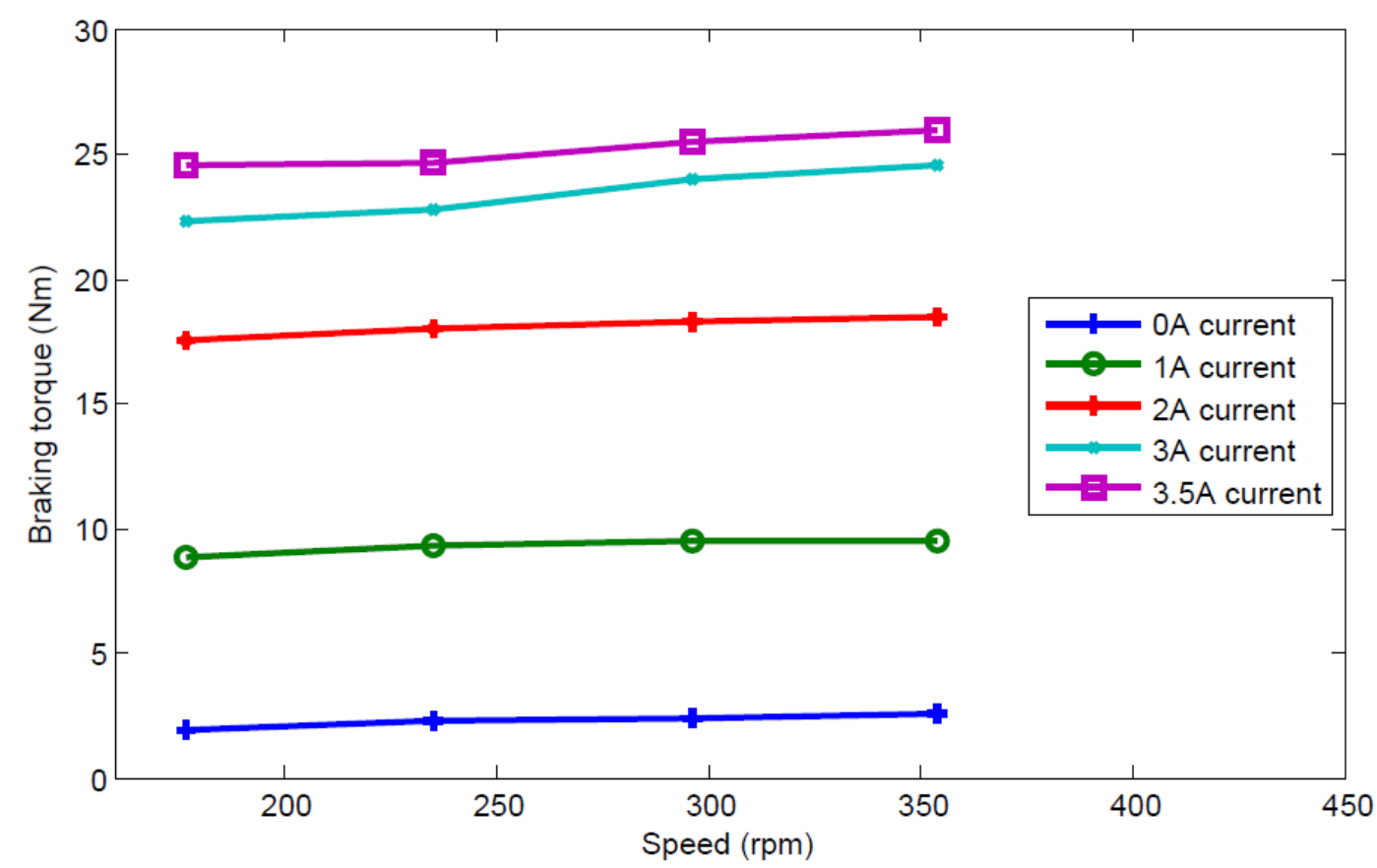

Figure 8. Experimental braking torque vs. speed for MRF-132DG.

\section{Comparison of Experimental and Analytical Results}

The analytical torque outputs are estimated based on Eq. (1), (2) and (3) mentioned earlier. The brake geometry is shown in Figure 2 while the brake configuration and design parameters are presented in Table 6. 
Table 6. Configuration and design parameters of MR brake under consideration.

\begin{tabular}{ll}
\hline Parameter & Configuration/Value of design parameter \\
\hline Type & Disc brake \\
Geometry & Rotary \\
Number of discs (N) & One \\
MR fluid & MRF-132DG \\
Gap size (h) & $1 \mathrm{~mm}$ \\
K (MRF dependent constant parameter) & $0.269 \mathrm{~Pa} \mathrm{~m} / \mathrm{A}$ \\
$\beta$ (MRF dependent constant parameter) & 1 \\
\hline
\end{tabular}

Table 7 presents values of analytical and experimental torque output at various input current and speed levels for MRF-132DG. Figure 9 shows the deviation between analytical and experimental output torque values for MRF-132DG at $354 \mathrm{rpm}$.

Table 7. Comparison of experimental and analytical results.

\begin{tabular}{cccccccccc}
\hline \multicolumn{10}{c}{ Torque (Nm) } \\
\hline $\begin{array}{c}\text { Speed } \\
\text { (rpm) }\end{array}$ & 177 & & \multicolumn{2}{c}{235} & & 296 & \multicolumn{2}{c}{354} \\
\hline $\begin{array}{c}\text { Current } \\
\text { (A) }\end{array}$ & Analytical & Exp & Analytical & Exp & Analytical & Exp & Analytical & Exp \\
\hline 1 & 12.88 & 8.82 & 13.37 & 9.31 & 13.89 & 9.51 & 14.38 & 9.51 \\
2 & 24.26 & 17.55 & 24.75 & 17.95 & 25.27 & 18.24 & 25.76 & 18.44 \\
3 & 35.64 & 22.26 & 36.13 & 22.75 & 36.65 & 23.93 & 37.14 & 24.52 \\
3.5 & 41.33 & 24.52 & 41.82 & 24.62 & 42.34 & 25.50 & 42.84 & 25.89 \\
\hline
\end{tabular}

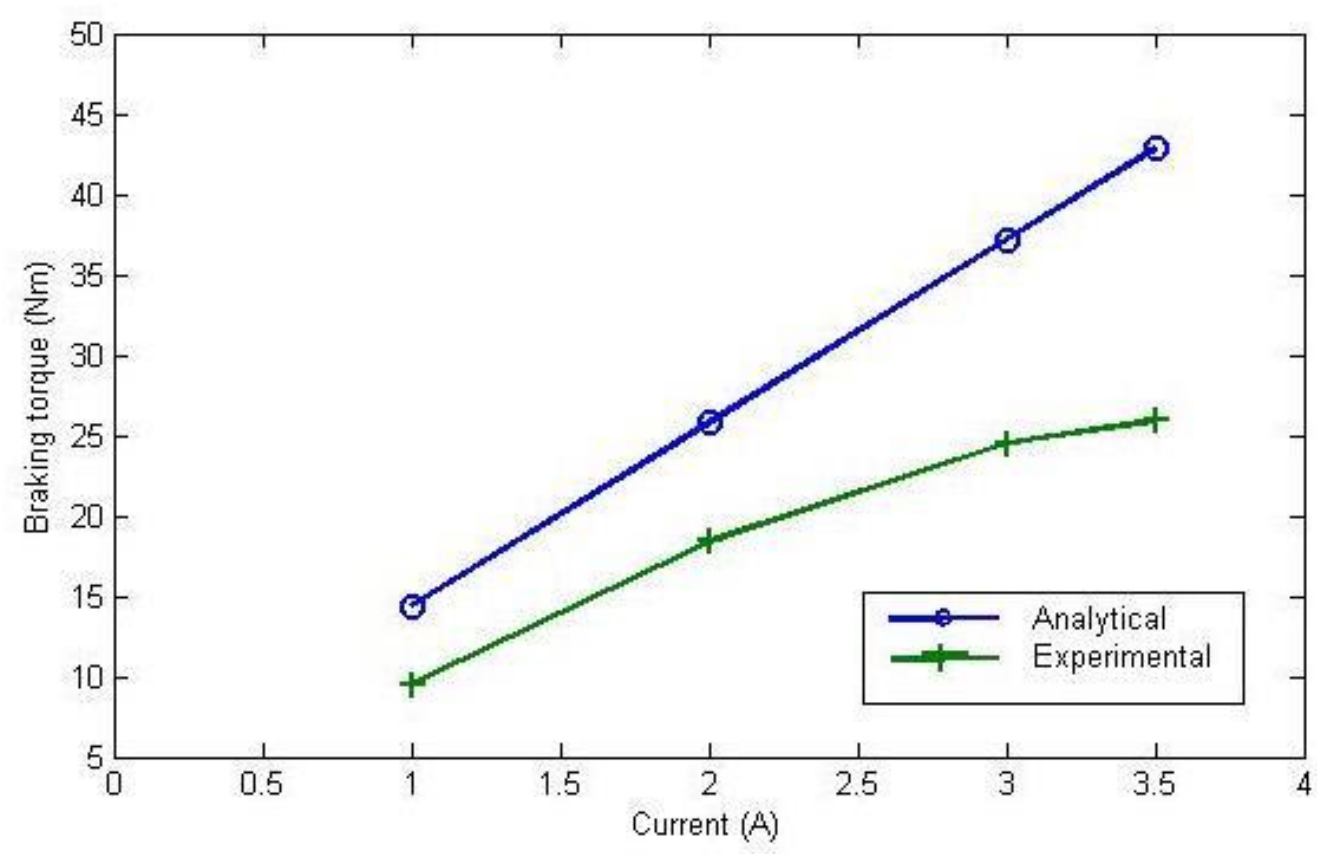

Figure 9. Experimental and analytical torque output.

The maximum experimental torque was observed to be $25.89 \mathrm{Nm}$ at $354 \mathrm{rpm}$ and $3.5 \mathrm{~A}$. The experimental torque at $2 \mathrm{~A}$ and $354 \mathrm{rpm}$ was recorded to be $18.44 \mathrm{Nm}$. The 
experimental torque is observed to be increasing with respect to input current and speed. However, the rise of torque value with respect to speed (row wise) is marginal as compared to rise of the same with respect to current (column wise). The percentage deviation between analytical and experimental torque values all across the data is found to be around $30-35 \%$. The difference is attributed to lack of accurate data regarding MRF constants $\beta$ and $\mathrm{k}$ which have been used during analytical calculations. The effect of rise in temperature on MR fluid viscosity and effect of sedimentation of MR fluid on yield stress value is not attributed for, in analytical equations. Also, the analytical equation considers the effect of speed on the torque along with input current. However, as it is visible from the plot (Fig. 8) above, the effect of speed is minimal in comparison to effect of input current. The experimental torque output of $18 \mathrm{Nm}$ recorded at $2 \mathrm{~A}$ and $354 \mathrm{rpm}$ is comparable to experimental torque output of $22 \mathrm{Nm}$ as reported by Karakoc et al. [2]. Karakoc et al. used two-disc brake with small sized disc ( $25 \mathrm{~mm}$ radius) while the present work uses single disc MRB with large disc (70 mm radius) for the experimentation.

\section{Effect of Braking Cycle on Torque Response}

In order to study effect of braking cycle, an experiment was conducted with MRF-132DG as working fluid wherein the brake is applied with three-minute gap between each braking application. Results were recorded and plotted as shown in Figure 10. The braking performance is compared in terms of brake torque for continuous braking and braking with three-minute gap between subsequent actuations. Such a braking cycle resembles urban road conditions with heavy to moderate traffic which requires brake applications intermittently. Marginal improvement of the order of around $1 \mathrm{Nm}$ is observed in output torque for the braking cycle. This marginal rise in output is attributed to reduction of temperature within the three-minute gap and hence increment in viscosity of MR fluid. Hence, it is concluded that effect of braking cycles on the braking performance of MRB is negligible.

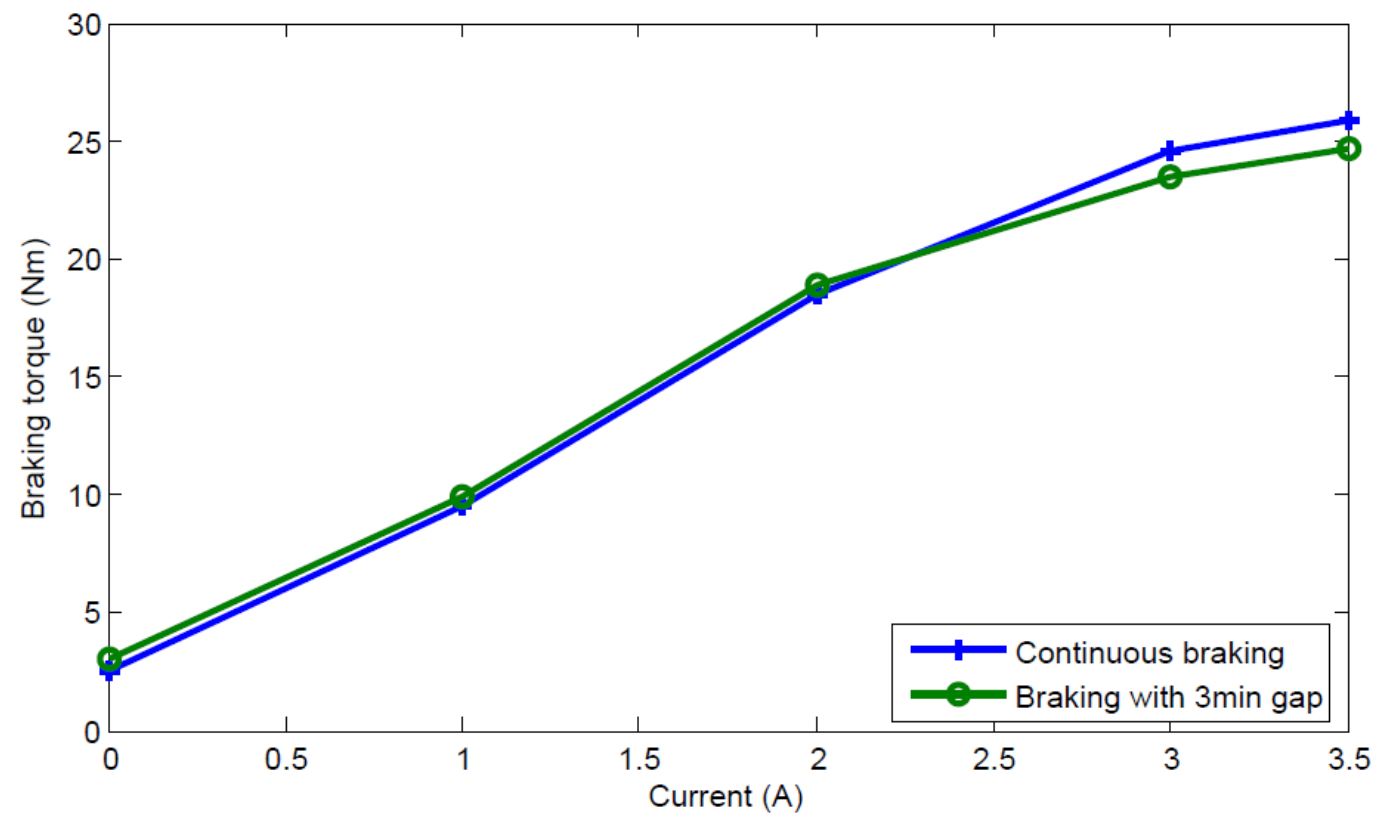

Figure 10. Effect of braking cycle on torque response. 


\section{Thermal Investigations}

Thermal investigations made during experimentation are presented in this section. Temperature of MR fluid was recorded with the help of infrared thermometer. During the experimental trials for output torque measurement, temperature of MR fluid within the MRB was also recorded. Figure 11 presents the plots of temperature variation for sets of current and speed values with MRF-132DG as working fluid.

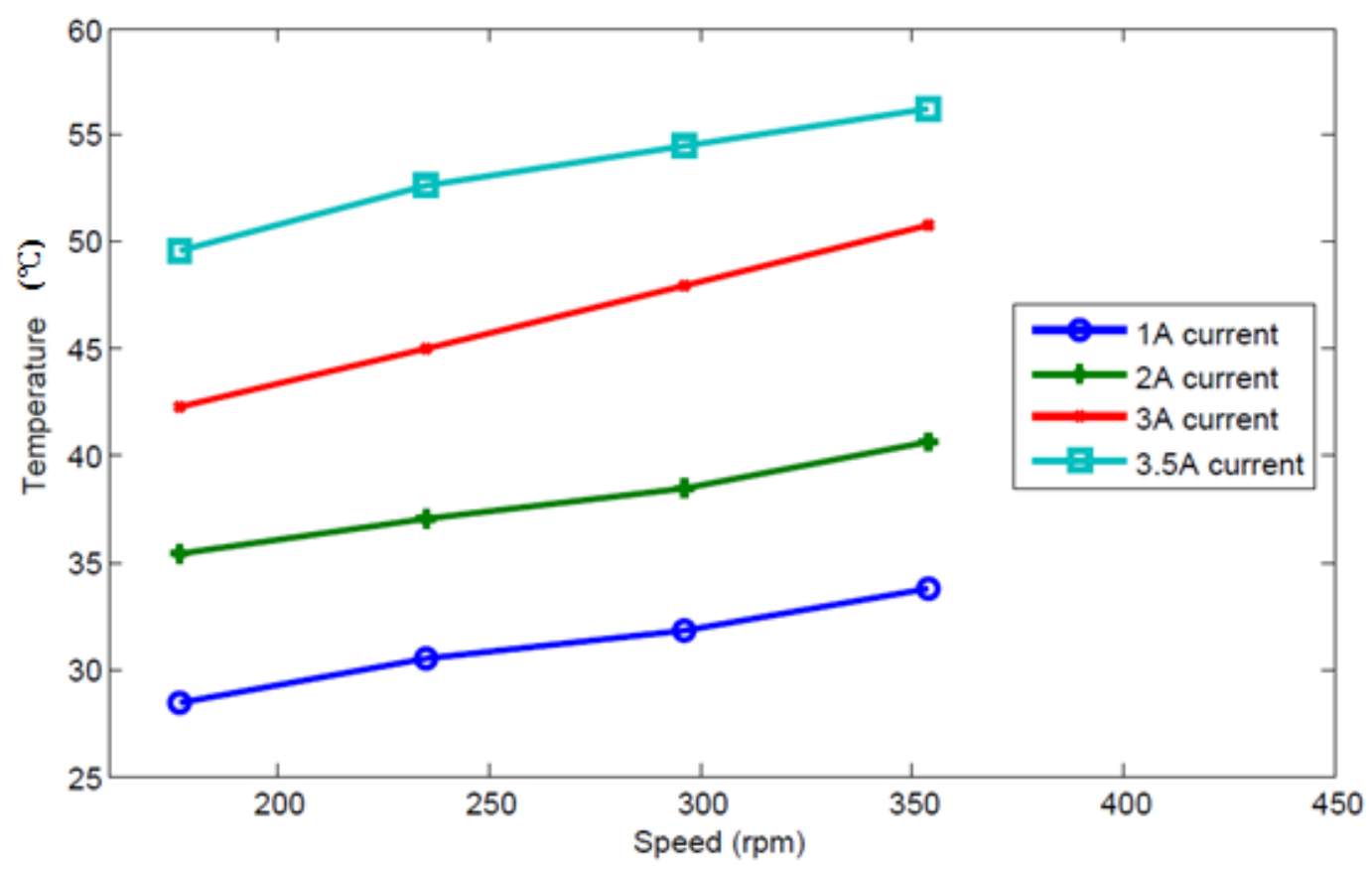

Figure 11. Variation of temperature for various speed and current levels.

\section{Thermal Investigation for A Drive Cycle}

Another experimental run was carried out in order to verify the temperature rise due to braking during a typical driving cycle. Such an investigation is warranted in order to consider practical cases like descending a hill or heavy urban traffic which demands frequent braking in small span of time. For conventional brakes, this requirement is taken care of by brake fade test. The imaginary driving cycle comprises of 10 minutes and the MRB is actuated after every single minute for $5 \mathrm{~s}$. The speed was maintained at $235 \mathrm{rpm}$ and input current level was $2 \mathrm{~A}$. The initial, intermediate and final temperatures for this driving cycle were noted and are presented in Table 8.

Table 8. Thermal observations during a drive cycle.

\begin{tabular}{cccccccccccc}
\hline Time (s) & 0 & 65 & 130 & 195 & 260 & 325 & 390 & 455 & 520 & 585 & 640 \\
\hline $\begin{array}{c}\text { Temperature } \\
\left({ }^{\circ} \mathrm{C}\right)\end{array}$ & 28.2 & 28.3 & 28.7 & 29.2 & 29.8 & 30.1 & 30.5 & 31.0 & 31.3 & 31.7 & 32.1 \\
\hline
\end{tabular}

The ambient temperature recorded at the beginning of the run was $28.2{ }^{\circ} \mathrm{C}$ and then gradually increased over the period of cycle. At the end of the drive cycle, the temperature recorded was $32.1{ }^{\circ} \mathrm{C}$ which means rise of $3.9^{\circ} \mathrm{C}$ was observed due to braking. The rise 
in temperature of MR fluid due to braking maneuver was found to remain well within the limits of operating temperature of MR fluid.

\section{Correlation Analysis of Experimental Data}

This section presents correlation analysis to validate the experimental data. Correlation analysis is used to establish the nature and strength of the relationship between braking torque output and influencing parameters viz. current and speed. Minitab 17 was used for the analysis. For the data under consideration, braking torque is dependent variable; current and speed are independents variables. Hypothesis proposed for this analysis with $95 \%$ confidence level was $\mathrm{H}_{0}: \mathrm{rh}_{0}=0$ (There is no correlation of torque with both current and speed). $\mathrm{H}_{\mathrm{a}}: \mathrm{rh}_{0} \neq 0$ (There is correlation of torque with both current and speed). $\mathrm{rh}_{0}$ is a coefficient of correlation. $\mathrm{H}_{0}$ is null hypothesis and $\mathrm{H}_{\mathrm{a}}$ is alternative hypothesis. The correlation analysis results and discussions thereof are presented as Table 9.

Table 9. Results of correlation analysis.

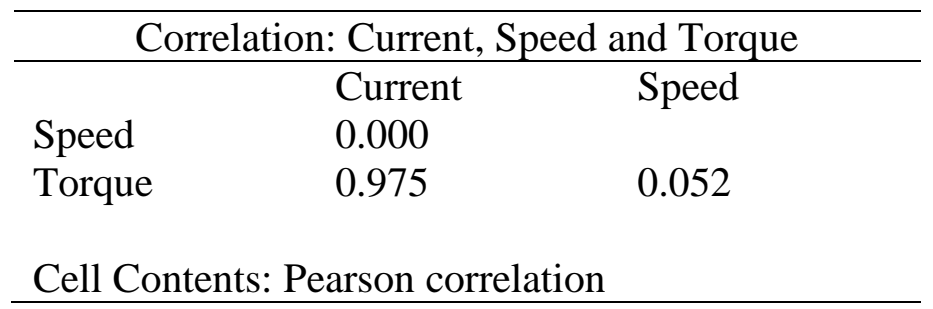

Coefficient of correlation for torque-current and torque-speed are 0.975 and 0.052 respectively; so, null hypothesis is rejected. There is strong positive correlation between torque and current since correlation coefficient is 0.975 which is close to 1 . Braking torque has very weak positive correlation with speed because correlation coefficient is nearly equal to 0 . This is also seen through scatter plot as shown in Figure 12 (a) and (b). Scatter plot of torque vs current shows that there is strong linear correlation between torque and current while scatter plot of torque vs speed does not show any linear relationship.

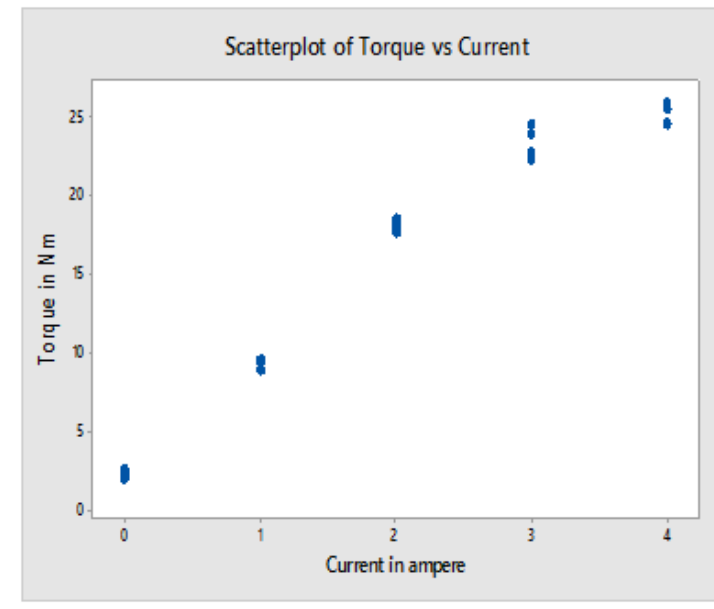

(a)

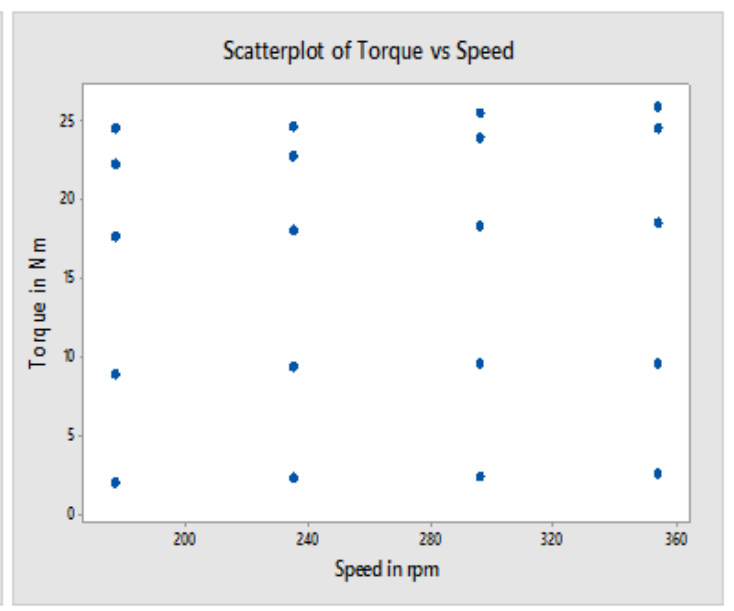

(b)

Figure 12. Scatter plot of torque vs. current and speed. 
Since there is correlation between variables; regression analysis is made using Minitab. The regression equation obtained is as Eq. (5). This equation is useful to forecast the braking torque output for any input current level.

Torque $=3.669+5.979 *$ Current

This work presents the design and magnetostatic analysis of MR brake. It reports experimental studies which were carried out on MR brake prototype with the help of specially designed evaluation set up. Measurement of magnetic flux density was done using gauss meter and the magnetic field intensity was estimated based on the same. The magnetic flux intensity at $2.5 \mathrm{~A}$ was found to be $78.58 \mathrm{kA} / \mathrm{m}$ which is very low as compared to magnetic saturation limit of around $250 \mathrm{kA} / \mathrm{m}$ of MRF-132DG. Thus, need is felt to optimize the magnetic circuit within the MRB in terms of size and magnetic field intensity. Objectives of experimental evaluation were to ascertain the effect of influencing parameters (speed and current) on output torque of MR brake as well as to verify the maximum torque output level and rise in temperature due to braking maneuver. The null hypothesis with $95 \%$ confidence level was framed as: there is no correlation of torque with both current and speed.

As a part of experimentation, the brake torque was recorded for angular speeds of 177, 235, 296 and $354 \mathrm{rpm}$ with current inputs ranging from 1 to $3.5 \mathrm{~A}$ for above mentioned MR fluids. For MRF-132DG as working fluid, the maximum brake torque output was observed to be $25.89 \mathrm{Nm}$ at $354 \mathrm{rpm}$ and $3.5 \mathrm{~A}$ of input current. This output is comparable with torque output of Karakoc et al. [2] (i.e $22 \mathrm{Nm}$ at $2 \mathrm{~A}$ ). The order of maximum torque output level is not sufficient enough to meet the braking requirements of proposed application. The difference between the torque estimated through magneto static analysis and experimental verifications could be attributed to lack of accurate information on MR fluid properties inputted during the analysis and effect of frictional torque being delivered by bearings and seals. During the development of prototype, plain carbon steel was used instead of aluminum. The temperature recorded during the experimentation was found to be well within the general operating temperature range of MR fluids.

Correlation and regression analysis were made using Minitab 17 in order to ascertain relationship between braking torque (dependent variable) and; current and speed (independent variables). The nature and strength of relationship was determined on the basis of Pearson correlation coefficient. It is found that input current is strongly and positively correlated with braking torque while speed has very weak positive correlation with braking torque for the MRB. However, the speed range considered in this study, corresponding to top speed of e-bicycle, was limited to $354 \mathrm{rpm}$. Effect of higher speed levels, say 800-1000 rpm, on brake torque output remains to be investigated. The regression equation obtained for the MR brake help estimate torque output for given level of input current.

\section{CONCLUSION}

Based on the above evaluations, it is concluded that though temperature rise during braking remains within operational limits of MR fluid, the torque output of proposed MR brake cannot meet the requirement of a light weight two-wheeler application like an ebicycle. Experimental single disc shear mode MRB prototype could generate around 25 $\mathrm{Nm}$ of braking torque i.e. $16 \%$ of braking torque requirement of e-bicycle under 
consideration. Correlation analysis confirms the significant influence of input current on the torque output of MR brake; however, speed doesn't influence the torque output in the same way. Thus, in order to meet braking requirements of automotive application, radical breakthrough in the form of yield stress level of MR fluid and/or MR brake design approach is warranted.

\section{ACKNOWLEDGEMENT}

The authors acknowledge Rajarambapu Institute of Technology, Rajaramnagar for the research grant released for this study.

\section{REFERENCES}

[1] Park EJ, Stoikov D, da Luz LF, Suleman A. A performance evaluation of an automotive magnetorheological brake design with a sliding mode controller. Mechatronics. 2006; 16(7): 405-416.

[2] Karakoc K, Park EJ, Suleman A. Design considerations for an automotive magnetorheological brake.Mechatronics. 2008; 18(8): 434-447.

[3] Li WH, Du H. Design and experimental evaluation of a magnetorheological brake. The International Journal of Advanced Manufacturing Technology. 2003; 21(7): 508-515.

[4] Park EJ, da Luz LF, Suleman A. Multidisciplinary design optimization of an automotive magnetorheological brake design. Computers \& Structures. 2008; 86(3): 207-216.

[5] Sukhwani VK, Hirani H. Design, development, and performance evaluation of high-speed magnetorheological brakes. Proceedings of the Institution of Mechanical Engineers, Part L: Journal of Materials: Design and Applications. 2008; 222(1): 73-82.

[6] Nguyen QH, Choi SB. Optimal design of an automotive magnetorheological brake considering geometric dimensions and zero-field friction heat. Smart Materials and Structures. 2010; 19(11), 115024.

[7] Nguyen PB, Choi SB. A new approach to magnetic circuit analysis and its application to the optimal design of a bi-directional magnetorheological brake. Smart Materials and Structures. 2011; 20(12), 125003.

[8] Nguyen QH, Choi SB. Optimal design of a novel hybrid MR brake for motorcycles considering axial and radial magnetic flux. Smart Materials and Structures. 2012; 21(5), 055003.

[9] Assadsangabi B, Daneshmand F, Vahdati N, Eghtesad M., Bazargan-Lari Y. Optimization and design of disk-type MR brakes. International Journal of Automotive Technology. 2011; 12(6):921-932.

[10] Younis A, Karakoc K., Dong Z., Park EJ, Suleman A. Application of SEUMRE global optimization algorithm in automotive magnetorheological brake design. Structural and Multidisciplinary Optimization. 2011; 44(6):761-772.

[11] Marannano GV, Virzì MG, Duboka Č. Preliminary design of a magnetorheological brake for automotive use. In Science and motor vehicles, international automotive conference. 2011, April; p.19-21.

[12] Sarkar C, Hirani H. Theoretical and experimental studies on a magnetorheological brake operating under compression plus shear mode. Smart Materials and Structures. 2013; 22(11), 115032. 
[13] Sarkar C, Hirani H. Design of magnetorheological brake using parabolic shaped rotating disc. International Journal of Current Engineering and Technology. 2015; 5: 719-724.

[14] Patil SR, Powar KP, Sawant SM. Thermal analysis of magnetorheological brake for automotive application. Applied Thermal Engineering. 2016; 98:238-245.

[15] Patil SR, Sawant SM. Reliability analysis of automotive magnetorheological brake: a qualitative approach. In ASME 2014 12th Biennial Conference on Engineering Systems Design and Analysis. 2014, July.

[16] Abdullah MA, Zainordin AZ, Hudha K. Performance evaluation of shaft speed control using a magnetorheological brake. International Journal of Automotive and Mechanical Engineering. 2015; 11, 2654.

[17] http://www.lord.com/products-and-solutions/magnetorheological-\%28mr\%29.xml (visited on 4 April 2015). 